\title{
Sin información no hay control: la Comisión Europea, el Consejo Europeo y el Consejo ante el Parlamento Europeo. Posibilidades y limitaciones de un modelo imperfecto de fiscalización política
}

\author{
Without Information there is no Accountability: the European Commission, \\ the European Council, the Council before the European Parliament. \\ Possibilities and Limits of an Imperfect Model of Political Control
}

\author{
José María Porras Ramírez \\ Catedrático de Derecho Constitucional de la Universidad de Granada \\ y Catedrático Jean Monnet de Derecho de la Unión Europea \\ jmporras@ugr.es
}

Sumario: I. Introducción.-II. El deber de la Comisión Europea de informar al Parlamento Europeo como presupuesto de la función de control. Naturaleza y principales manifestaciones.-III. La obligación de la Comisión Europea de responder a las preguntas e interpelaciones del Parlamento Europeo.-IV. Las comparecencias del Consejo Europeo y del Consejo ante el Parlamento Europeo.-V. Conclusiones.

Resumen: A fin de contribuir a una más completa realización del principio democrático en el nivel europeo, las instituciones dotadas de carácter intergubernamental y naturaleza política que concurren en el desarrollo de la gobernanza de la Unión han intensificado su colaboración e intercambio de información con el Parlamento Europeo, rindiendo así cuenta de sus actuaciones ante la Cámara. No obstante, lo han hecho con muy desigual intensidad. Así, la Comisión ha asumido ese deber constante a través de las más diversas formas de comparecencia y suministro documental de datos e informes, facilitando así los acuerdos, al tiempo que se asegura un control universal y efectivo de sus actos, que puede llegar a comportar la asunción de responsabilidades. Sin embargo, esa colaboración e intercambio de información con el Parlamento Europeo no se observa, en igual proporción, en los casos del Consejo y, sobre todo, del Consejo Europeo, instituciones que, si bien también están llamadas a explicar sus actuaciones ante la Cámara, lo hacen sólo en las condiciones fijadas por su respectivo reglamento interno; privilegio éste que disminuye considerablemente su alcance, lo que constituye motivo de crítica y de solicitud de corrección. 
Palabras clave: Deber de información, función de control político, Parlamento Europeo, Comisión Europea, Consejo Europeo y Consejo

Abstract: In order to contribute to a more complete realization of the democratic principle at the European level, the institutions endowed with intergovernmental character and political nature that concur in the development of the governance of the Union have intensified their collaboration and exchange of information with the European Parliament, thus rendering account of their proceedings before the Chamber. However, they have done so with very unequal intensity. Thus, the European Commission has assumed this constant duty through the most diverse forms of appearance and documentary supply of data and reports, facilitating agreements and the accountability of its acts and decisions. However, this collaboration and exchange of information with the European Parliament is not observed, in equal proportion, with the Council and, above all, the European Council. This is because these institutions that, although they are also called to give an account of their actions before the Chamber, do so only under the conditions set by their respective internal regulations, a privilege that greatly decreases its reach, which is a reason for criticism and correction request.

Keywords: Duty of information, accountability, European Parliament, European Commission, European Council, Council.

\section{Introducción}

A fin de contribuir a una más completa realización del principio democrático en el nivel europeo, las instituciones dotadas de carácter intergubernamental y naturaleza política que concurren en el desarrollo de la gobernanza de la Unión han intensificado su colaboración e intercambio de información con el Parlamento Europeo, rindiendo así cuenta de sus actuaciones ante la Cámara. No obstante, lo han hecho, tal y como en este trabajo se pone de manifiesto, con desigual intensidad. Así, mientras que la Comisión ha asumido ejemplarmente ese deber a través de las más diversas formas de comparecencia y suministro documental de datos e informes, facilitando así los acuerdos, al tiempo que asegura un control universal y efectivo de sus actos, que puede llegar a comportar la asunción de responsabilidades; sin embargo, esa colaboración e intercambio de información con el Parlamento Europeo no se observa, en igual proporción, en los casos del Consejo y, sobre todo, del Consejo Europeo. No en vano, estas dos instituciones, si bien también están llamadas a explicar sus actuaciones ante la Cámara, habida cuenta de la relevancia de las competencias que ejercen, lo hacen sólo en las condiciones fijadas por su respectivo reglamento interno; 
privilegio éste que, a la postre, disminuye considerablemente su alcance. Este hecho constituye un motivo fundado de crítica y de solicitud de corrección. La extensión, si bien adaptada a sus peculiaridades, del modelo de información y control establecido entre el Parlamento y la Comisión, que tan buenos resultados viene ofreciendo en los últimos años, se presenta así como propuesta destinada a contribuir al debate en curso acerca de las reformas institucionales que han de afectar al desarrollo de la gobernanza política de la Unión.

\section{El deber de la Comisión Europea de informar al Parlamento Europeo como presupuesto de la función de control. Naturaleza y principales manifestaciones}

La decidida voluntad de atribuir una posición central a la democracia parlamentaria en la redefinición de la arquitectura institucional de la Unión, se evidencia en la creación de una relación particularmente estrecha entre el Parlamento Europeo y la Comisión. De ese modo, en tanto que interlocutor preferente del órgano ejecutivo de referencia, el Parlamento Europeo ha ido fraguando, de forma paulatina, una conexión política intensa con esa institución, consciente de que la misma ha dejado definitivamente de ser la «Alta Autoridad» de una organización internacional, pretendidamente independiente, llamada a actuar conforme a criterios técnico-funcionales de eficacia y experiencia, al tiempo que reducida a la preparación y ejecución de las decisiones adoptadas por el Consejo ${ }^{1}$.

Así, a tenor de su nuevo estatus, reflejado hoy en el art. 17 TUE, la Comisión ha recibido el reconocimiento que merece en los Tratados, en su condición de actor político de la mayor relevancia, encargado de promover el interés general de la Unión. De ahí que, a ese fin, sea de su competencia tomar las iniciativas adecuadas ${ }^{2}$, lo que conlleva su sujeción al control del Parlamento, ante el que asume una responsabilidad colegiada por sus actos. Tal vinculación no ha hecho sino aumentar, como han puesto de manifiesto los acuerdos interinstitucionales y el Reglamento del Parlamento Europeo (RPE). De ese modo, la exigencia de una relación fiduciaria entre ambas instituciones (art. 17.7 TUE), favorecida por la simultaneidad de los mandatos que les afectan, ha propiciado su «asociación especial» («special part-

${ }^{1}$ Paolo Ridola, «La parlamentarizzazione degli assetti istituzionali dell`Unione Europea fra democrazia rapresentativa e democrazia participativa», en Diritto comparato e Diritto costituzionale europeo, editado por Paolo Ridola (Torino, Giappichelli, 2010): 325-342.

2 Paolo Ponzano, «La Commissione Europea: composizione e ruolo nel sistema istituzionale dell’Unione», en Il diritto della Unione Europea (2004): 501-517. 
nership»), nexo político éste que se ha demostrado determinante a la hora de fortalecer, tanto la vigencia y proyección del principio democrático en el marco institucional de la Unión, como el buen funcionamiento del llamado «método comunitario» de toma de decisiones ${ }^{3}$.

Ciertamente, la ampliación del diálogo constructivo y la fluida circulación de la información entre las dos instituciones, mejorando la cooperación en materia de procedimientos y planificación, requiere que, tanto el Presidente de la Comisión, como los comisarios, informen constantemente al Parlamento de sus diferentes iniciativas y actuaciones (art. 230.1 TFUE). Así, inicialmente, corresponde al Presidente de la Comisión definir las orientaciones con arreglo a las cuales la Comisión desempeñará sus funciones (art. 17.6 TUE y art. 124.1 RPE). De ahí trae causa la obligación que esta institución asume, en tanto que órgano colegiado, de comparecer ante el Parlamento Europeo para presentar la programación anual y plurianual de la Unión (art. 17.1 TUE). Como es bien sabido, el programa plurianual, que tiene como premisa unas conclusiones conjuntas alcanzadas por el Consejo, el Parlamento y la propia Comisión (art. 126 RPE), va acompañado de una lista de propuestas legislativas y no legislativas para los años siguientes; mientras que el anual, cuyo desarrollo requiere una declaración conjunta de esas mismas instituciones, abarca tan solo al año siguiente. De esa forma, mediante la trabajosa preparación y el desarrollo concertado de ambas agendas se proporciona a la asamblea información pormenorizada sobre las prioridades cuya ejecución desea promover la Comisión, conforme a su programa de trabajo (art. $38 \mathrm{RPE}$ ). Así, según se ha demostrado, de forma especial, en los últimos años, la confección y aplicación de ambos programas exigen el constante intercambio de puntos de vista, los cuales sirven de base para emprender un diálogo estructurado, con vistas a alcanzar los acuerdos necesarios para la adopción de las medidas propuestas ${ }^{4}$.

Como testimonio de una relación que tiene un carácter continuo, se ha previsto que, durante el primer semestre de cada año, los comisarios emprendan un diálogo con las comisiones parlamentarias competentes, tanto

${ }^{3}$ Paul Craig, «The role of the European Parliament under the Lisbon Treaty», en The Lisbon Treaty. EU Constitutionalism without a Constitutional Treaty?, editado por Stefan Griller \& Jacques Ziller (Vienna, Springer, 2008): 109-134. Deirdre Curtin, Executive Power of the European Union. (Oxford, Oxford University Press, 2009): 45; Edoardo Gianfrancesco, «Article 17: the European Commission», en The Treaty on the European Union. A Commentary, editado por Hermann Joseph Blanke \& Stelio Mangiameli (Heildelberg, Springer, 2013): 270.

${ }^{4}$ Bruno De Witte, Alexander H. Trechsel, Dragana Damjanovic, Elin Hellquist, Josef Hien, Paolo Ponzano, Legislating after Lisbon. New Opportunities for the European Parliament. (Florence, European University Institute, Robert Shuman Centre for Advanced Studies, 2010): 3 
para preparar el futuro Programa de Trabajo de la Comisión, como para ejecutar el vigente. Paralelamente, la Conferencia de Presidentes de Comisión mantiene un intercambio regular con el Vicepresidente de la Comisión encargado de las relaciones interinstitucionales, a fin de evaluar los trabajos en curso, esto es, el estado de aplicación del Programa de Trabajo y la preparación del futuro. De este modo, dicha Conferencia controla los resultados del diálogo bilateral realizado, presentándolos en junio por medio de un informe sucinto, del que se da traslado a la Comisión. Y sobre la base de dicho informe, el Parlamento adopta una resolución, en el período parcial de sesiones del mes de julio, en la que tiene ocasión de exponer su posición, incluyendo, en particular, las solicitudes basadas en informes de iniciativa legislativa ${ }^{5}$. Se evidencia así su capacidad de supervisión, seguimiento y control acerca del grado de cumplimiento de sus compromisos por parte de la Comisión. La mayor fragmentación política de la asamblea, apreciable en las dos últimas legislaturas, y la creciente conciencia adquirida por los diputados acerca de la importancia de su misión, ha contribuido, sin duda, a intensificar una relación bilateral que se revela cada vez más exigente, tal y como, a título de destacado ejemplo, ha puesto de manifiesto la ardua negociación, entre ambas instituciones, del Código Comunitario de Visados ${ }^{6}$.

Además, ese estrecho contacto se evidencia, de forma sobresaliente, cuando, cada año, en el primer período parcial de sesiones del mes de septiembre, se celebra un debate sobre el estado de la Unión, el cual obliga al Presidente de la Comisión a hacer un balance del año en curso y una previsión de las prioridades que se marca el órgano ejecutivo que dirige para el año siguiente. A este último fin, transmite por escrito al Parlamento las principales directrices que informan la preparación del Programa de Trabajo de la Comisión para el año próximo. Y, seguidamente, esto es, a partir de ese mes, los comisarios y las comisiones parlamentarias competentes comienzan a reunirse para intercambiar opiniones acerca de las prioridades respectivas. Tales reuniones culminan con la que sostienen la Conferencia de Presidentes y el colegio de comisarios, y aquélla y el Presidente de la Comisión, si procediere. Como resultado de esos encuentros bilaterales se adopta, en octubre, el programa de trabajo de la Comisión para el año siguiente, que el Presidente de aquélla presentará en el Parlamento formalmente. Como respuesta al mismo,

5 José María Porras Ramírez, «La iniciativa legislativa indirecta del Parlamento Europeo: ¿un cambio en el método comunitario de toma de decisiones?», Revista Española de Derecho Europeo, 70, (2019): 23-48.

${ }^{6}$ Informe sobre la Propuesta de Reglamento del Parlamento Europeo y del Consejo por el que se modifica el Reglamento (CE) n. ${ }^{\circ} 810 / 2009$, por el que se establece un Código Comunitario sobre Visados. Comisión LIBE del Parlamento Europeo, de 6 de diciembre de 2018. (Ref. A8-0434/2018). 
el Parlamento celebra un debate, particularmente ágil y dinámico, al tiempo que dotado de una notable repercusión pública, aprobando finalmente una resolución en el período parcial de sesiones del mes de diciembre, que contendrá las conclusiones a las que en aquél se llegaron, las cuales orientarán los futuros trabajos e iniciativas de la Comisión ${ }^{7}$.

Se viene así a poner de manifiesto cómo a lo largo del año se asiste a una colaboración e intercambio constante de información entre la Comisión y el Parlamento Europeo, tanto por medio de la presentación de informes o documentos, como a través de la comparecencia en la Cámara de los miembros responsables, todo lo cual permite al Ejecutivo de la Unión acordar con los órganos parlamentarios competentes el calendario legislativo ${ }^{8}$, al tiempo que, simultáneamente, rinde cuentas ante la asamblea de sus actuaciones pasadas, presentes y futuras 9 .

Por si esto no fuera suficiente, según prevé el artículo 133 RPE, «el Presidente del Parlamento invitará al Presidente de la Comisión, al miembro de la Comisión responsable de las relaciones con el Parlamento o, previo acuerdo, a otro miembro de la Comisión, a realizar una declaración ante el Parlamento después de cada una de las reuniones de la Comisión, en la que explique las principales decisiones adoptadas, salvo si, por razones de calendario, o debido a la relevancia política relativa del asunto, la Conferencia de Presidentes decide que no es necesario. Dicha declaración irá seguida de un debate de una duración mínima de treinta minutos, durante el cual los diputados podrán formular preguntas breves y precisas». Se consigue así que, en ocasiones particularmente relevantes, la Comisión comparezca, a través de su máximo representante, y dé cuenta de sus actos, sometiéndose al escrutinio y la fiscalización de la asamblea ${ }^{10}$. Complementariamente, los miembros de la Comisión están facultados para, en cual-

7 Cfr. art. 142 del Reglamento del Parlamento Europeo y el Anexo 4 al Acuerdo marco sobre las relaciones entre el Parlamento Europeo y la Comisión Europea. DO L 304, 20.11.2010, p. 47.

8 Vid., asimismo, el Acuerdo interinstitucional entre el Parlamento Europeo, el Consejo de la Unión Europea y la Comisión Europea sobre la mejora de la legislación. DO L 123, 12.5.2016, p. 1-14. Conforme a su apartado $7 .^{\circ}$, tras la adopción del programa de trabajo de la Comisión, el Parlamento el Consejo y la propia Comisión intercambiarán opiniones y acordarán una declaración conjunta sobre la programación interinstitucional anual en la que se establezcan prioridades y objetivos amplios.

9 Paola Piroddi, «Il Parlamento europeo nel Tratatto de Lisbona tra democrazia rappresentativa e democrazia partecipativa», Rivista Italiana di Diritto Pubblico Comunitario, n. ${ }^{\circ} 3$ (2011): 801-837. También, Richard Corbett, Francis Jacobs, \& Darren Neville, The European Parliament, (London, John Harper, 2016), 310-312.

10 Así, por ejemplo, la grave crisis desencadenada entre los Estados Unidos e Irán, en enero de 2020, ha obligado a la Comisión a fijar su posición y a exponerla, a solicitud propia, ante el Parlamento Europeo. 
quier momento, conforme al art. 132 RPE, solicitar al Presidente del Parlamento autorización para hacer uso de la palabra y efectuar una declaración ante la Cámara, la cual podrá verse seguida de un debate, susceptible de concluir con una resolución ${ }^{11}$.

Para asegurar y facilitar tales comparecencias, el Acuerdo marco sobre las relaciones entre el Parlamento Europeo y la Comisión Europea establece que ésta habrá de dar prioridad a su presencia en las sesiones plenarias o reuniones de otros órganos del Parlamento, en detrimento de otros eventos o invitaciones que, a un mismo tiempo, se produzcan. A tal efecto, la Comisión garantizará que, como norma general, los miembros de la Comisión estén presentes en las sesiones plenarias que aborden los puntos del orden del día que sean de su responsabilidad, siempre que el Parlamento así lo solicite. Esto es aplicable a los proyectos de orden del día preliminares aprobados por la Conferencia de Presidentes durante el período parcial de sesiones anterior. A tal efecto, el Parlamento procurará que, como norma general, los puntos del orden del día de los períodos parciales de sesiones que sean responsabilidad de un miembro de la Comisión se encuentren agrupados. De ese modo, con el fin de asegurar la presencia de los miembros de la Comisión, el Parlamento se compromete a hacer todo lo posible para mantener sus proyectos finales de orden del día. Por lo tanto, cuando el Parlamento modifique su proyecto final de orden del día, o cuando mueva los puntos dentro del orden del día, en el marco temporal de un período parcial de sesiones, el Parlamento informará inmediatamente a la Comisión. Así ésta hará lo necesario para garantizar la presencia de un miembro responsable competente. No obstante, para facilitar este propósito se contempla que la Comisión proponga la inclusión de puntos en el orden del día, a más tardar en la reunión de la Conferencia de Presidentes que decida sobre el proyecto final de orden del día de un período parcial de sesiones. Y el Parlamento deberá tener en cuenta esas propuestas ${ }^{12}$.

Asimismo, de forma análoga, las comisiones parlamentarias buscarán el mantenimiento de sus proyectos de orden del día y agendas. Por lo tanto, si deciden extraordinariamente alterarlos, se informará inmediatamente a la Comisión al respecto. Pero, en cualquier caso, las comisiones parlamentarias se esforzarán por respetar un plazo razonable para así permitir la presencia de miembros de la Comisión ${ }^{13}$. Todo sea con tal de que se facilite su

11 A este respecto destacan las frecuentes comparecencias del Alto Representante de la Unión para Asuntos Exteriores y Política de Seguridad, en su calidad de Vicepresidente de la Comisión.

12 Acuerdo marco sobre las relaciones entre el Parlamento Europeo y la Comisión Europea. DO L 304, 20.11.2010, p. 47, n. ${ }^{\circ} 45$.

${ }^{13}$ Acuerdo marco, ibídem, n. 48. 
comparecencia, a fin de asegurar su colaboración y propiciar, al tiempo, el control de sus actuaciones.

Además, como ya se ha adelantado, los miembros de la Comisión serán oídos a petición propia. En ese sentido, el artículo 132 RPE establece que aquéllos podrán, en cualquier momento, solicitar permiso al Presidente de la Cámara para hacer una declaración. Y corresponde a dicho Presidente decidir cuándo se puede hacer aquélla y si debe verse seguida de un debate completo o de un turno de preguntas breves y precisas de los diputados, de treinta minutos de duración. En todo caso, el Parlamento decidirá si cabe cerrar el debate con una resolución. Así sucederá a menos que se haya previsto un informe sobre idéntico asunto en el mismo período parcial de sesiones o en el siguiente, salvo que el Presidente, por razones excepcionales, disponga otra cosa. Pero, en todo caso, y sin perjuicio de lo establecido en el art. 230 TFUE, el Parlamento y la Comisión acordarán, se entiende que flexiblemente, las reglas generales relativas a la distribución del tiempo de uso de la palabra entre las instituciones ${ }^{14}$.

Finalmente, es preciso indicar que la Comisión no sólo presentará prospectivamente sus programas anual y plurianual de actividades, dando cuenta del desarrollo y ejecución de aquéllos, sino que habrá de someter a la valoración que de aquéllos tenga a bien efectuar el Parlamento, un informe general, consecuentemente retrospectivo, acerca de las actuaciones realizadas por la Unión durante el último año, en desarrollo de las diferentes políticas expuestas y defendidas por la propia Comisión, que poseen un carácter estratégico para la misma (arts. 233 TFUE y 142 RPE).

El informe en cuestión hará así referencia, si nos atenemos, a título de ejemplo, al presentado en 2019, a los progresos realizados por la Comisión en materia de impulso al empleo, el crecimiento y la inversión; el desarrollo de un mercado único digital conectado; la creación de una Unión de la energía resiliente con una política climática prospectiva; la preparación de un próximo presupuesto a largo plazo de la Unión Europea; la apuesta por un mercado interior más equitativo e integrado, con una base industrial fortalecida; el diseño de una unión económica y monetaria más profunda y justa; el desarrollo de una política comercial equilibrada y progresiva para encauzar la globalización; la realización de un espacio de justicia y derechos fundamentales basado en la confianza mutua; la prosecución en los avances experimentados en relación con la apuesta por una nueva política sobre migración; la referencia a los progresos hechos en aras de hacer de Europa un actor más potente en el escenario mundial; y,

${ }^{14}$ Acuerdo marco, ibídem, n. ${ }^{\circ} 4$.

Cuadernos Europeos de Deusto 
en fin, el análisis de los pasos dados para alcanzar una Unión de cambio democrático ${ }^{15}$.

Con vistas a facilitar el conocimiento y examen de dicho informe general, la Comisión lo publicará anualmente, tal y como ordena el art. 249.2 TFUE, no después de un mes antes de la apertura de las sesiones del Parlamento Europeo, que se inician habitualmente en febrero. Como se ha indicado, en dicho informe la Comisión dará cuenta de las iniciativas y logros alcanzados durante el año pasado, o que se encuentran aún en curso de desarrollo, en relación a las prioridades a las que se había comprometido ante el propio Parlamento. Se trata, por tanto, de un documento extenso y detallado que contiene una información muy útil para los miembros de la asamblea, ya que permite a los mismos hacer un seguimiento de los asuntos, al tiempo que faculta a los diputados para el desarrollo de un control efectivo y una eventual demanda de responsabilidad política a sus principales actores, de conformidad con los Tratados ${ }^{16}$. El examen de este documento general complementa el análisis de otros informes parciales que sirven para la preparación del programa legislativo de la Comisión o que ilustran acerca de la ejecución de sus más relevantes políticas sectoriales.

En suma, ese deber constante de información de la Comisión al Parlamento, a través de las más diversas formas de comparecencia y suministro documental de datos e informes, garantiza el intercambio de aquélla, facilita los acuerdos y asegura el control universal y efectivo de sus actos, haciendo posible, en fin, el ejercicio pleno de la función representativa por parte de los diputados. De esa forma se permite a la Cámara la realización de un juicio político de oportunidad o conveniencia, acerca de tales actuaciones ${ }^{17}$, que certificará, en su caso, su concordancia con las orientaciones políticas establecidas por quienes ostentan la representación directa de la voluntad de los ciudadanos de la Unión. Se refuerza así la legitimidad y la responsabilidad de la Comisión, se otorga transparencia, agilidad y coordinación a los procedimientos deliberativos y decisorios, y se favorece, en fin, el funcionamiento

15 Vid., a modo de significativo ejemplo, La UE en 2018. Informe general sobre las actividades de la Unión Europea». 15 de febrero de 2019. Dirección General de Comunicación. Comisión Europea. https://publications.europa.eu

${ }^{16}$ Sin embargo, el Art. 233 TFUE, a diferencia de lo que disponía su predecesor, el Art. 200 TCE, no asume la previsión incorporada al Art. 24 del Tratado CECA, conforme al cual la discusión del informe general anual de la Comisión puede ser causa directa de una moción de censura. Vid. Así, Marie Blocteur, «Article 200», en Commentaire article par article des Traité UE et CE, dir. por Isabelle Pingel (Bruxelles, Bruylant, 2010): 1348-1349.

17 Acerca de la naturaleza de esta modalidad de control, vid., Manuel Aragón Reyes, «El control parlamentario como control político», Revista de Derecho Político, 23 (1986): 9-39. 
articulado y conjunto de las instituciones ${ }^{18}$. No en vano, su discusión se produce en sesión parlamentaria abierta, ante el Pleno de la Cámara, según prevé el art. 142 RPE, desarrollándose en el marco del ejercicio de las funciones ordinariamente asignadas al Parlamento por los Tratados (art. 14 TUE).

Ciertamente, las informaciones suministradas por la Comisión al Parlamento Europeo, las cuales cabe asimilar a aquéllas que contraen el deber de aportar, asimismo, el Consejo Europeo (art. 15.6 d) TUE) y el Banco Central Europeo (art. 284.3 TFUE), confieren al Parlamento un «poder de debatir» extraordinariamente relevante. Sin embargo, dicho poder ha sido, a veces, minusvalorado, al considerarlo una mera expresión de un «parlamentarismo débil» («soft parlamentarism»), una manifestación más del deber general de supervisión y seguimiento de las actividades de las instituciones de la Unión, en general, y de la Comisión, en particular, que asiste al Parlamento Europeo ${ }^{19}$. Así, se ha llegado, incluso, a señalar que tal poder se vincula con la exigencia democrática de publicidad, apertura y transparencia que ha de informar las actuaciones desarrolladas por aquéllas, de conformidad con el art. 15 TFUE.

Mas no es así, ya que estamos en presencia de un supuesto o modalidad característica de control «ex post» ordinario, que permite a la Cámara, conforme a criterios políticos de conveniencia y oportunidad, apreciados libre y subjetivamente, proceder al examen de cuantos actos desarrolla la Comisión, de conformidad con el mandato previamente recibido ${ }^{20}$. Consecuentemente, el «acto de informar» viene a expresar el compromiso adquirido por el agente de rendir cuentas de su conducta e intenciones ante el órgano que lo legitima y del que trae causa, en la forma, el tiempo y el lugar predefinido por la normativa establecida. De esa forma, la materialización de ese deber de informar por medio de comparecencias, declaraciones o la presentación de informes por parte de la Comisión actúa como presupuesto que habilita para el inicio de un procedimiento público y externo de control parlamentario, el cual puede llegar a desembocar extraordinariamente en la exigencia de responsabilidad política, con la consiguiente imposición efectiva de sanciones ${ }^{21}$.

18 Jean Victor Louis, «Une Commission politique», Cahiers de Droit Européen, 50, n..$^{\circ}$ 3, (2014): 485-499. También, vid., David Spence \& Geoffrey Edwards, The European Commission, (London, John Harper, 2006): 22.

19 Robert Schütze, European Union Law (Cambridge, Cambridge University Press, 2018): 165-166.

${ }^{20}$ Carol Harlow, Accountability in the European Union (Oxford, Oxford University Press, 2002): 84; Vernon Bogdanor, Legitimacy, Accountability and Democracy in the European Union. (London, A Federal Trust Report, 2007): 62.

${ }^{21}$ Mark Bovens, «Anlysing and assesing accountability. A conceptual framework», European Law Journal, 13, n. 4 (2007), 447; Deirdre Curtin, Executive power of the European Union (Oxford, Oxford University Press, 2009): 256-258. 
En definitiva, la extensión adquirida por las competencias de la Comisión, de acuerdo con los Tratados, y la posición central otorgada simultáneamente al Parlamento Europeo en la arquitectura institucional de la Unión, dada la proyección adquirida en aquélla por el principio de la democracia representativa ${ }^{22}$, justifica sobradamente que dicho órgano de gobierno deba someter sus actuaciones al escrutinio de un foro representativo y pluralista, generando así un debate abierto y público acerca de su alcance concreto. Y una discusión política de esa índole sólo se hace posible cuando quien la promueve cuenta con la información imprescindible, a esos efectos ${ }^{23}$. Información que no sólo le ha de ser transmitida, sino convenientemente expuesta y justificada, interpretada, en fin, por su autor, a los efectos de hacerla merecedora de una valoración final, en el marco de un proceso público y transparente de rendición de cuentas.

Por eso, la resolución que, en su caso, emita el Parlamento confirmará o rechazará, siquiera parcialmente, las políticas desarrolladas por la Comisión, incluyendo un juicio político acerca de los actos realizados por el Ejecutivo europeo. Así, aunque, en apariencia, tales resoluciones parezcan una formalidad sin consecuencias, lo cierto es que, a menudo, albergan críticas, que pretenden, ya contribuir a la reorientación de esas políticas, ya a la profundización en las mismas. No en vano toda resolución contiene siempre una sanción política de las actuaciones que la Comisión ha protagonizado. De modo que, si el Parlamento considera que el Ejecutivo europeo se ha apartado apreciablemente de los compromisos adquiridos con anterioridad ante la asamblea, o sus actos suponen un cumplimiento insatisfactorio de los mismos, la Comisión se expone a consecuencias políticas negativas muy variadas. A tal fin, el Parlamento cuenta con un elenco significativo de medios e instrumentos que no cabe despreciar ${ }^{24}$.

Así, atendiendo a experiencias pasadas, dichas técnicas de control se pueden sustanciar en la reprobación de uno o varios comisarios, en la petición de su dimisión o la solicitud de su destitución, en atención a la deficiente ejecución de las políticas asumidas. Además, a través de sus críticas, cuando éstas son mayoritariamente secundadas, el Parlamento puede llegar a deteriorar apreciablemente la imagen pública de la institución, re-

${ }^{22}$ Armin Von Bogdandy, «Founding principles», en Principles of European Constitutional Law, ed. por Armin Von Bogdandy y Jürgen Bast (New York/Munich, Hart/C.H. Beck, 2010): 11; José María Porras Ramírez, «Article 10: Representative Democracy», en The Treaty on the European Union. A Commentary, ed. por Hermann Joseph Blanke \& Stelio Mangiameli (Heildelberg, Springer, 2013): 420.

${ }_{23}$ Stelio Mangiameli, «Article 14: The European Parliament», en The Treaty on the European Union. A Commentary, op. cit., 599.

${ }^{24}$ Mark Bovens, «Anlysing and assesing accountability. A conceptual framework», op. cit., 462; Deirdre Curtin, Executive power of the European Union, op. cit., 271-274. 
prochándole su mala gestión. Asimismo, no es raro que la asamblea amenace a la Comisión con futuras restricciones presupuestarias si no se secundan o cumplen sus directrices; o que, como medida más severa, llegado el caso más extremo, conmine a la Comisión con el anuncio de la presentación de una moción de censura que pueda suponer, en su caso, su destitución (art. 234 TFUE) ${ }^{25}$.

\section{La obligación de la Comisión Europea de responder a las preguntas e interpelaciones del Parlamento Europeo}

En consecuencia, el deber de la Comisión de comparecer e informar de sus actos, a fin de hacer posible el diálogo y la cooperación en torno a objetivos y procedimientos comunes, sienta las bases para el ejercicio del control parlamentario de sus actuaciones. Tal función, a través de la cual cabe analizar e interpretar, desde una perspectiva amplia, cuantos cometidos desempeña hoy tanto éste como cualquier otro Parlamento del mundo ${ }^{26}$, se materializa, ordinariamente, de forma dinámica y continua, a través de la evacuación de preguntas $^{27}$. Dicho instrumento de fiscalización ${ }^{28}$ de los actos de la Comisión se plasma así en una escueta y concreta demanda pública de explicación acerca de una información, hecho o situación puntual, en relación con un determinado aspecto de la actividad que desarrolla habitualmente el Ejecutivo europeo. Su solicitud corresponde a los miembros u órganos del Parlamento a quienes asiste esta facultad, conforme al Reglamento de la Cámara. Y su intención no es otra que contrastar subjetivamente la oportunidad y conveniencia de una decisión o conducta particular que ha tenido como protagonista a la Comisión, a quien se insta a que rinda cuentas ante el Parlamento por la adopción o realización de aquélla.

${ }^{25}$ La caída de la Comisión Santer, en 1999, por acusaciones de irregularidades y fraude, constituye, sin duda, el ejemplo más extremo de lo indicado. Marc Blanquet, «Le contrôle parlementaire européen su la crise de la vache folle», Revue du Marché Commun et de l'Union Europeéne, 420 (1998): 457-470.

${ }^{26}$ Vid., Francisco Rubio Llorente, «El control parlamentario», en La forma del poder. Estudios sobre la Constitución (Madrid, Centro de Estudios Políticos y Constitucionales, 1993): 255.

27 Paolo Ponzano, «La Commissione Europea...», op. cit., p. 512; Stelio Mangiameli, «The institutional design of the European Union after Lisbon», en The European Union after Lisbon. Constitutional basis, economic order and external action (Heildelberg, Springer, 2012): 99.

${ }^{28}$ Como referencia clásica acerca del origen y evolución de las preguntas parlamentarias, conforme al modelo británico, cfr, Thomas Erskine May, Treatise on the Law, Privileges, Proceedings and Usage of Parliament (Cambridge, Cambridge University Press, 2015): 624. Contemporáneamente, entre otros, Andrea Manzella, «Interrogazione e interpellanza parlamentare», en Enciclopedia dell Diritto, Vol. XXII, (Milano, Giuffé, 1972): 406-427. 
Como, asimismo, se constata en la mayoría de los Estados miembros, en el ordenamiento de la Unión se contemplan dos tipos preguntas. En primer lugar, han de considerarse las, normalmente más genéricas y relevantes, "preguntas con solicitud de respuesta oral», las cuales suelen ir seguidas de un debate, hecho éste que acrecienta su importancia. Sin duda, se trata de las vías de control que alcanzan una mayor difusión y repercusión pública, dada su notable significación política. En consonancia con su mayor trascendencia ${ }^{29}$, de conformidad con el art. $136 \mathrm{RPE}$, las llamadas «preguntas orales» pueden formularse al Ejecutivo de la Unión a través, únicamente, de una comisión parlamentaria, un grupo político o un número de miembros del Parlamento Europeo que alcancen, al menos, el umbral mínimo establecido de cuarenta diputados. Tales preguntas deben ir acompañadas de una solicitud para que se incluyan en el orden del día del Parlamento. Y así se les dará trámite, siempre y cuando no se refieran a asuntos sobre los cuales la Comisión ya haya informado al Parlamento sobre su posición, mediante comunicación escrita ${ }^{30}$.

Esta modalidad de preguntas ha de trasladarse por escrito al Presidente de la Cámara, quien las remitirá de inmediato a la Conferencia de Presidentes, a fin de que este órgano decida acerca de su inclusión en el proyecto de orden del día. De no hacerlo dicho órgano parlamentario, en un plazo de tres meses desde su presentación, aquéllas decaerán. Seguidamente, en tanto que preguntas dirigidas a la Comisión, deberán remitirse a su destinatario, al menos una semana antes de la sesión en cuyo orden del día se hayan incluido. Excepcionalmente, expresando así las debilidades del control parlamentario en relación a ciertos asuntos o materias insuficientemente comunitarizados, se ha previsto que si la pregunta se refiere a alguna cuestión concerniente a la política común de seguridad y defensa, no se apliquen esos plazos, instándose a la Comisión a que manifieste su respuesta, siquiera, «en un plazo razonable para que el Parlamento se mantenga debidamente informado».

En todo caso, la formulación de la pregunta en el Pleno corresponderá a un diputado designado al efecto por los autores de aquélla. Si no lo hace, la pregunta decaerá, pero si lo hace, el destinatario responderá oralmente, tal y como se solicitó, sobre la base de las notas e informes que, al efecto, le preparen los servicios administrativos de él dependientes. Tras la contestación,

${ }_{29}$ Por citar un ejemplo relevante de la Legislatura 2019-2024, vid., la »pregunta con solicitud de respuesta oral» O-000046/2019, sobre la «Estrategia de la UE sobre discapacidad para después de 2020», formulada por cuatro diputados en representación del Grupo Popular Europeo. http://europarl.europa.eu/plenary/es/parliamentary-questions.html

30 Acuerdo marco sobre las relaciones entre el Parlamento Europeo y la Comisión Europea, op. cit., n. ${ }^{\circ} 16$. 
habida cuenta de su relieve, cabe la posibilidad, siguiéndose aquí el modelo francés, de que se lleve a cabo un debate, correspondiendo al Presidente del Parlamento la decisión acerca de si el mismo concluye, o no, con una resolución que dé lugar a un pronunciamiento, tras la oportuna votación de la Cámara $^{31}$. En definitiva, las preguntas orales seguidas de debate permiten la discusión en el Pleno de asuntos concretos que poseen, aun así, una especial resonancia pública, no llegando a afectar, sin embargo, a cuestiones de política general ${ }^{32}$.

Complementariamente, se ha regulado un sobresaliente «turno de preguntas a la Comisión», el cual se encuentra inequívocamente inspirado en el incisivo «question time» británico ${ }^{33}$. El mismo se ha previsto que se realice en cada período parcial de sesiones, con una duración de noventa minutos como máximo. Versará sobre uno o más temas horizontales específicos que decidirá la Conferencia de Presidentes, con una antelación de un mes respecto al referido período parcial de sesiones ${ }^{34}$. Los comisarios invitados a participar por la Conferencia de Presidentes serán responsables de una cartera relacionada con el tema o temas horizontales específicos sobre los que se les vayan a formular preguntas. Pero el número de comisarios a los que se invite se limitará a dos por cada período parcial de sesiones. No obstante, será posible invitar excepcionalmente a un tercer comisario, dependiendo del tema o temas horizontales específicos escogidos para el turno de preguntas.

En cuanto a su desarrollo, a fin de contribuir a su agilidad y dinamismo, se ha dispuesto con acierto que el turno de preguntas no sea objeto de un reparto por adelantado. De ese modo, el Presidente del Parlamento se asegurará de que los diputados que tengan opiniones políticas diferentes y que provienen de diferentes Estados Miembros, posean la oportunidad de formular una pregunta sucesivamente. Así, cada diputado tendrá sólo un minuto para expresar la cuestión y el comisario dispondrá únicamente de dos minutos para responder. Tras ello, se contempla la posibilidad de que el diputado pueda formular una pregunta suplementaria o «repregunta», de una duración máxima de treinta segundos, que guarde relación directa con la pregunta principal. En tal supuesto, se concederán dos minutos al comisario para dar una respuesta suplementaria, para lo que no contará ya con la ayuda de informes previos. En cualquier caso, ha de insistirse en que, tanto las preguntas principales, como las suplementarias, han de guardar relación directa con el tema horizontal específico que se haya acordado tratar, porque, de lo con-

31 Art. 136.5, en relación con el 132 RPE.

32 León Martínez Elipe, Tratado de Derecho Parlamentario. Volumen I: Fiscalización parlamentaria y extraparlamentaria. Inspección parlamentaria. (Madrid, Aranzadi, 2000): 298-299.

33 R Schütze, European Union Law, op. cit., 165.

34 Art. 137.1 RPE. 
trario, el Presidente rechazará previsiblemente su admisión. De la confrontación suscitada en el turno de preguntas suele resultar un debate muy vivo, que permite una incisiva y esclarecedora exploración de los puntos de vista respectivos, dando lugar, consiguientemente, a una exhaustiva rendición de cuentas por parte de los distintos miembros de la Comisión.

Asimismo, se contempla que se puedan celebrar turnos de preguntas específicos y regulares con el Presidente de la Comisión, de conformidad con las directrices establecidas por la Conferencia de Presidentes ${ }^{35}$. Este turno de preguntas especial y, sin duda, muy sobresaliente, constará de dos partes: la primera, se desarrollará con los presidentes de los grupos políticos o sus representantes, realizándose de forma totalmente espontánea; y la segunda, se dedicará monográficamente a un asunto político que se acuerde previamente, como muy tarde el jueves antes del período parcial de sesiones correspondiente, pero sin preguntas preparadas.

Además, siguiendo el modelo del turno de preguntas al Presidente de la Comisión, se ha introducido también un turno de preguntas extraordinario dirigido a los miembros de la Comisión, incluido el Vicepresidente y el Alto Representante de la Unión para Asuntos Exteriores y Política de Seguridad; el cual estará lógicamente relacionado con la cartera del correspondiente miembro de la Comisión ${ }^{36}$.

En segundo lugar, de conformidad con el Art. 138 RPE, se contemplan las llamadas «preguntas con solicitud de respuesta escrita», que son, sin duda, de entre todas las existentes, las más numerosas, ya que cualquier diputado, grupo político o comisión puede formularlas al Ejecutivo de la Unión, por lo que no se necesita su aprobación por parte de la Conferencia de Presidentes, al constituir una responsabilidad exclusiva de sus autores. Este tipo de preguntas se remiten ágilmente, en formato electrónico, al Presidente de la Cámara, que ha de decidir motivadamente sobre su admisión, si alberga dudas fundadas al respecto. Cada solicitante legitimado podrá enviar un máximo de veinte preguntas durante un período de tres meses consecutivos. No obstante, se contempla la posibilidad de que las preguntas sean avaladas por otros diputados distintos de su autor, si bien computarán únicamente en el cupo asignado a éste ${ }^{37}$.

35 Art. 137.3

36 Acuerdo marco,op. cit., n. ${ }^{\circ} 46$.

37 Como ejemplo paradigmático de «pregunta con solicitud de respuesta escrita», formulada durante la actual Legislatura 2019-2024, vid. la que tiene como objeto inquirir a la Comisión sobre «el uso de las ayudas de la Unión concedidas a Grecia e Italia en materia de asilo, en vista del Informe n. ${ }^{\circ}$ 24/2019 del Tribunal de Cuentas Europeo» (E-004414/2019), formulada por ocho diputados europeos. http://europarl.europa.eu/plenary/es/parliamentaryquestions.html 
Por lo general, el destinatario responderá a las preguntas en un plazo de seis semanas a partir de su transmisión. No obstante, los diputados, los grupos políticos o las comisiones podrán designar cada mes una de sus cuestiones, calificándola como "pregunta prioritaria», por lo que su destinatario deberá contestarla en el plazo más breve de tres semanas a partir de su transmisión. Mas si el destinatario no puede hacerlo en ese plazo, tratándose de una pregunta prioritaria; o alega que no le es posible dentro de las seis semanas de plazo que se le otorga para contestar a una pregunta considerada no prioritaria, la comisión competente podrá decidir su renovada inclusión en el orden del día de su siguiente reunión ${ }^{38}$. En todo caso, de las preguntas y sus respuestas, con sus correspondientes anexos, quedará registro fehaciente, al publicarse debidamente en el sitio web del Parlamento.

Conforme al Anexo III al Reglamento del Parlamento Europeo, las preguntas con solicitud de respuesta escrita tendrán, siempre, las siguientes notas características, tanto formales como materiales: especificarán claramente el destinatario a quien deben transmitirse mediante los canales interinstitucionales habituales; incidirán exclusivamente en el ámbito de competencias del destinatario; serán de interés general; serán concisas y contendrán una pregunta comprensible; no excederán las doscientas palabras; no contendrán lenguaje ofensivo; no se referirán a asuntos estrictamente personales; y no contendrán más de tres subpreguntas.

En cualquier caso, se han previsto restricciones destinadas a evitar un uso abusivo o exorbitante de una figura orientada, más bien, a la obtención por parte de los diputados de una concreta información en poder de la Comisión, a la que se quiere otorgar publicidad ante la Cámara. Así, en relación a dichos límites, se contempla que si en los seis meses anteriores se ha formulado y contestado una pregunta idéntica o similar, o se constata que la pregunta simplemente persigue recabar información acerca del seguimiento de una resolución específica del Parlamento sobre la cual la Comisión ya ha contestado por escrito mediante una comunicación de seguimiento emitida en los seis meses anteriores, la Secretaría transmitirá al autor una copia de la pregunta anterior y la respuesta previa de la comunicación de seguimiento. Por lo tanto, dicha pregunta no se remitirá al destinatario, a menos que el Presidente del Parlamento así lo decida, a la luz de cambios significativos y en respuesta a una solicitud motivada del autor ${ }^{39}$.

Con un mismo propósito de evitar preguntas redundantes o insistentes sobre una cuestión ya tratada, se ha dispuesto que, si a través de una pre-

38 Un ejemplo de «pregunta escrita prioritaria» lo constituye la formulada por una diputada acerca de la polémica reforma del sistema judicial emprendida en Polonia P-000035/2020. http://europarl.europa.eu/plenary/es/parliamentary-questions.html

39 Anexo III, 4. $^{\circ}$. 
gunta se pretende solicitar información objetiva o estadísticas de las que ya disponen los servicios de estudio del Parlamento, aquélla no se transmitirá al destinatario sino a esos servicios, salvo que el Presidente decida lo contrario a petición del autor. Además, las preguntas referentes a asuntos relacionados podrán ser reagrupadas por la Secretaría en una sola pregunta, a fin de recibir así una respuesta conjunta ${ }^{40}$.

Habida cuenta de su sencillez procedimental ha de insistirse en que esta es la vía más empleada en el Parlamento Europeo para trasladar ordinariamente preguntas a los miembros de la Comisión. También es la más llana y cómoda para su destinatario, que puede contestar a las preguntas que se le formulen, valiéndose de la asistencia de los servicios administrativos de que dispone, sin necesidad de comparecer presencialmente. De ese modo, se evita la potencial erosión de su imagen pública que podría derivarse de una comparecencia y un debate poco satisfactorios para el mismo. Pero más allá de eso, lo cierto es que se trata de una figura cuya proliferación, sin duda excesiva, resta dinamismo y espontaneidad al control parlamentario, que, en cierto sentido, se formaliza y oculta a través de un procedimiento escrito, lejano a la inmediatez que vívidamente expresa la confrontación oral de pareceres («to meet face to face»), característica de un sistema parlamentario ${ }^{41}$.

Finalmente, es necesario referirse a las interpelaciones, figura ésta más tardíamente introducida en el Reglamento del Parlamento Europeo, que la regula, en la actualidad, en su art. 139. Dado que exigen una respuesta escrita, procede diferenciar a las interpelaciones de las preguntas que requieren un mismo tipo de contestación. Así, a diferencia de éstas, sólo estará legitimado para formularlas un grupo político, y, por tanto, no un diputado a título individual. Además, su objeto consistirá en la indagación acerca de un asunto de interés general y relevante trascendencia pública. Se trata, por tanto, de un medio de control parlamentario habitualmente más incisivo y complejo, cuyo objetivo no consiste en otorgarle, meramente, publicidad en el Parlamento a cierta actuación puntual de la Comisión, sino que pretende, más bien, inquirir sobre la orientación política seguida por aquélla en relación a un asunto de notoria importancia, insinuando un juicio del que puede derivarse en el futuro una sanción ${ }^{42}$.

\footnotetext{
40 Anexo III, 5. .

${ }^{41}$ Federico Russo \& Matt Wiberg, «Parliamentary questioning in 17 European Parliaments: some steps towards comparison», The Journal of Legislative Studies, 17, n. 3 (2011): 215.

42 Para un concepto de interpelación, figura ésta importada del Derecho francés y vinculada, inicialmente, a los regímenes asamblearios revolucionarios, vid. León Martínez Elipe, Tratado de Derecho Parlamentario, op. cit., 303. Como acabado ejemplo de interpelación dirigida a la Comisión, véase aquélla que tiene por objeto alcanzar un mejor conocimiento acerca de la situación existente en Pakistán en relación a la violación de los derechos fundamentales de las mujeres. G-000005/2018. http://europarl.europa.eu/plenary/es/parliamentary-questions.html
} 
Así, las interpelaciones se someterán por escrito al Presidente de la Cámara, no pudiendo superar las quinientas palabras. Si se muestran conformes con el Reglamento del Parlamento, el Presidente las remitirá inmediatamente a su destinatario para que responda por escrito. En todo caso, a fin de evitar un uso desmedido de este instrumento, existe únicamente la posibilidad de presentar treinta interpelaciones al año, debiendo la Conferencia de Presidentes garantizar la distribución equitativa de las mismas entre los grupos políticos, no pudiendo ninguno de ellos presentar más de una al mes. La contestación escrita se enviará en un plazo de seis semanas a partir de la transmisión de la interpelación, pero si la Comisión agota ese plazo sin contestar, aquélla se incluirá, previa solicitud del autor, en el proyecto definitivo de orden del día del Parlamento.

Sin duda, lo más relevante en relación con esta figura estriba en que la contestación a la interpelación abre la posibilidad de que, si un número de diputados o de grupos políticos necesario para alcanzar, al menos, el umbral medio de la Cámara así lo solicita, se incluya la interpelación en el proyecto definitivo de orden del día del Parlamento. La finalidad no es otra que dar paso a un debate en el Pleno. Aun así, en cada período parcial de sesiones sólo podrán debatirse tres interpelaciones, a menos que la Conferencia de Presidentes excepcione esta limitación.

Conforme al procedimiento establecido, un diputado perteneciente al grupo político autor de la iniciativa expondrá la interpelación, acompañada de una declaración explicativa, a la que contestará también oralmente su destinatario. El debate subsiguiente, de forma previsible, conducirá a la presentación y votación de una propuesta de resolución de la Cámara. Dicho pronunciamiento posee una clara proyección exterior, ya que consigue el sometimiento de la Comisión a una revisión de su orientación política del que puede resultar, bien la confirmación de la confianza puesta en ella, bien un cuestionamiento o reprobación de su actuación, del que puede llegar a derivarse una futura exigencia de responsabilidad política. Esto explica su importancia y la atención prioritaria que a las interpelaciones parlamentarias dispensa la Comisión ${ }^{43}$.

\section{Las comparecencias del Consejo Europeo y del Consejo ante el Parlamento Europeo (Art. 230.3 TFUE)}

A su vez, el Tratado de Funcionamiento de la Unión Europea ha previsto, en el párrafo tercero de su art. 230, que el Consejo y, también, como

43 Asimismo, ha de tenerse en cuenta que las restricciones, tanto formales como materiales, que establece el Anexo III al Reglamento del Parlamento Europeo, en relación a las preguntas con solicitud de respuesta escrita, son extensibles a las interpelaciones. 
novedad más significativa, en relación al art. 197.4 TCE ${ }^{44}$, el Consejo Europeo, den cuenta de sus actuaciones ante el Parlamento Europeo, si bien «en las condiciones fijadas por el (respectivo) reglamento interno...». De ese modo, se consigue la extensión, aunque sea de manera parcial, del ejercicio de la función de control parlamentario, inicialmente prevista, tan solo, en relación a la Comisión, con respecto a las acciones desarrolladas por parte de aquellas instituciones de clara naturaleza intergubernamental, dotadas de una notable relevancia política. En este sentido, el Tratado de Lisboa, más que innovar, lo que hizo fue formalizar una loable práctica política, desarrollada convencionalmente en las últimas décadas. En cualquier caso, ya sea por una vía u otra, lo cierto es que así se contribuye a situar al Parlamento Europeo en una posición central en la compleja arquitectura institucional de la Unión ${ }^{45}$, al reconocérsele la potestad, durante demasiado tiempo inexistente, de fiscalización política de las actuaciones promovidas por tales instituciones ${ }^{46}$.

En lo que se refiere al Consejo Europeo, institución ésta desgajada del Consejo conforme al Tratado de Lisboa, esa proyección de la función de control parlamentario viene a expresar una necesidad perentoria. No en vano, es aquélla una institución, justificada originariamente por la creciente inestabilidad económica internacional y la necesidad de dotar a la Unión de un liderazgo político efectivo ${ }^{47}$, que, en tanto que reunión de los Jefes de Estado y de Gobierno de los Estados miembros, recibe el cometido de dar a la Unión los impulsos necesarios para su desarrollo, definiendo, por consenso de sus miembros, las orientaciones y prioridades políticas generales (art. 15.1 TUE). Una función tan sobresaliente, que se traduce en el ejercicio de decisivas competencias, la faculta para incidir en múltiples y muy relevantes ámbitos, algunos, incluso, sustraídos, en buena medida, al habitual «procedimiento comunitario» de toma de decisiones y a la actividad de control del Tribunal de Justicia. En este sentido, destacan las actuaciones que el Consejo Europeo promueve en referencia a la acción exterior de la Unión, en relación con la cual le compete señalar sus «objetivos e intereses estratégicos» (art. 22.1 TUE); el ámbito de la Política Exterior y de Seguridad Común, en el que determina las orientaciones generales, incluyendo las

${ }^{44}$ Marie Blocteur, «Article 197 TCE», en Commentaire article par article des Traité UE et $C E$, dir. Isabelle Pingel (Bruxelles, Bruylant, 2010): 1343.

45 Gregorio Garzón Clariana, «El control parlamentario del Ejecutivo de la Unión Europea», ed. por Francesc Pau i Valls (Coord.), El control del Gobierno en democracia. XIX Jornadas de la Asociación Española de Letrados de Parlamentos (Madrid, Tecnos, 2013): 19.

46 Anthony Arnull \& Daniel Wincott, Accountability and Legitimacy in the European Union, (Oxford, Oxford Univesrity Press, 2002): 22.

47 Phillip Dann, «The political Institutions», en Principles of European Constitutional Law, ed. Armin Von Bogdandy \& Jürgen Bast, (Oxford, Hart/C.H. Beck/Nomos, 2011): 261. 
que rigen la Política Común de Seguridad y Defensa (arts. 24 y 26 TUE); y el Espacio de Libertad, Seguridad y Justicia, con respecto al cual define las orientaciones estratégicas de la programación legislativa y operativa (art. 68 TFUE). Además, revelando su condición de centro de gravedad político y auténtico eje del poder de la Unión, el Consejo Europeo aparece dotado de unas competencias extraordinarias, conforme a las cuales lleva a cabo un desarrollo institucional básico de los Tratados, lo que le permite, incluso, completar las previsiones de aquéllos ${ }^{48}$. Y, a su vez, con carácter, también, excepcional, el Consejo Europeo adquiere la condición de instancia arbitral en la solución de los conflictos ${ }^{49}$. Es, pues, sin duda, la instancia máxima de gobierno general de la Unión ${ }^{50}$.

Y es, precisamente, esa configuración extraordinaria de la institución, que la lleva a ser titular de trascendentales competencias, de alcance cuasi constitucional, las cuales se ponen especialmente de manifiesto en situaciones de crisis, lo que desajusta la estructura de gobierno de la Unión, de acuerdo con la lógica tendencial, de carácter parlamentario, que, desde la aprobación, en Maastricht, del Tratado de la Unión Europea, le es propia. Ciertamente, su protagonismo redimensiona el proceso de toma de decisiones europeo y el propio principio del equilibrio institucional, que se torna así precario ${ }^{51}$. No en vano, el Consejo Europeo no somete su actuación a la iniciativa de la Comisión; margina al Parlamento Europeo, ante el que no se considera responsable; y ve como sus actos quedan genéricamente exentos de control jurisdiccional por parte del Tribunal de Justicia, que circunscribirá su fiscalización, únicamente, a los supuestos en que aquéllos desplieguen efectos jurídicos frente a terceros e impliquen la imposición de medidas restrictivas a personas físicas o jurídicas, en el marco de la Política Exterior y de Seguridad Común (art. 24 TUE, en relación a los arts. 40 TUE y 263 y 275 TFUE).

La distorsión que genera esta previsión de los Tratados, al suponer la adición de un actor de naturaleza intergubernamental, destinado a incidir,

${ }^{48}$ Cfr. Arts. 7, 14.2, 15.5, 17.7, 18.148 .7 TUE; 86.4, 235.1, 236 a), 236 b), 244, 283, 312.2 y 355.6 TFUE y Protocolos 4,9 y 32 , primordialmente.

${ }^{49}$ Como ponen de manifiesto los Arts. 48, 82.3, 87.3 TFUE y 5.4 y 5.5 del Protocolo n. ${ }^{\circ} 19$.

${ }^{50}$ Califica, así, justamente, al Consejo Europeo de auténtico «señor de la Unión», Ingolf Pernice, «Il Consiglio Europeo e il Presidente dell`Unione Europea: quale `leadership’ democratica in Europa?», Diritto e Cultura, n. ${ }^{\circ} 1$ (2003): 181.

${ }^{51}$ Con carácter general, acerca de este principio tendencial de la Unión, vid., Koenraad Lenaerts \& Amaryllis Verhoeven, «Institutional balance as a guarantee for democracy in EU governance», en Good governance in Europe's integrated market, ed. por Christian Joerges \& Rénaud Dehousse (Oxford, Oxford University Press, 2002): 35; y, en relación al Tratado de Lisboa, cfr., Maria Pia Iadicicco, «Le riforme istituzionali nell'Unione Europea dopo Lisbona: un equilibrio precario», en Il processo di integrazione europea tra crisi di identità e prospettive di represa, ed. por Lorenzo Chieffi, (Torino, Giappichelli, 2009): 72. 
siquiera sea de manera externa e indirecta, pero en todo caso de modo muy relevante, en el desarrollo del llamado «método comunitario de toma de decisiones ${ }^{52}$, pretende, en parte, corregirse con iniciativas como la suscitada por la llamada «propuesta Juncker». Esta auspicia la unificación de las presidencias del Consejo Europeo y de la Comisión, a fin de establecer una coordinación efectiva entre ambas instituciones impulsoras de la acción de gobierno, sometiéndolas, al tiempo, a la confianza y el control político efectivo del Parlamento Europeo ${ }^{53}$. En tanto en cuanto este objetivo, «de lege ferenda», se alcanza, lo cierto es que el Consejo Europeo presenta, a día de hoy, una mínima y casi simbólica conexión con la asamblea, lo que viene a manifestar los límites u obstáculos interpuestos a una completa parlamentarización de las estructuras institucionales de la Unión.

Aun así, el art. 15.6 d) TUE ha venido a disponer que el Consejo Europeo, por medio de su Presidente, «al término de cada reunión..., presentará un informe al Parlamento Europeo ${ }^{54}$; previsión ésta que ha permitido al Reglamento de la Cámara regular un deber de comparecencia e información, que se erige en condición necesaria para el ejercicio de un, siquiera, tibio control de sus actuaciones. De tal forma, ha determinado, en su art. 132, que corresponderá al Presidente del Parlamento la decisión acerca de cuándo podrá hacer aquél esa declaración, y si ésta se verá seguida de un debate completo o de un turno de preguntas breves y precisas de los diputados, de treinta minutos de duración. Asimismo, este mismo precepto reglamentario establece que los demás miembros del Consejo Europeo podrán, en cualquier momento, pedir permiso al Presidente del Parlamento para hacer una declaración ante la Cámara, la cual podrá verse seguida de un procedimiento análogo de control. Seguidamente, de acordarse un debate, el Parlamento decidirá si cabe cerrarlo con una resolución, la cual habrá de ser propuesta, como suele ser habitual, por una comisión, un grupo político o el número de diputados necesarios para alcanzar el umbral mínimo de la Cámara. Tras ello, dicha resolución se someterá, si procediere, a votación en el primer turno de votaciones posible ${ }^{55}$.

52 El Consejo Europeo «no ejercerá función legislativa alguna» (Art. 15.1 TUE).

53 Jean Paul Juncker, Discurso sobre el estado de la Unión 2017, de 13 de septiembre de 2013. Comisión Europea. Bruselas, 13.09.2017 COM (2017) 823 final. Comunicación de la Comisión al Parlamento Europeo, al Consejo Europeo, al Consejo y al Banco Central Europeo.

54 Vid., asimismo, el Art. 5 del Reglamento interno del Consejo Europeo (DO L 315, de 02.12.2009, p. 52 y DO L 325, de 11.12.2009, p. 36, rectificación DO L 55, de 5.3.2010, p. 83).

55 Jam Willem Sap, «The European President», European Constitutional Law Review, 1 (1), (2005), 47; Jan Werts, The European Council. (London, John Harper publishing, 2008):, 12; Jean Paul Jacqué, «Institutions de 1'Union», Revue Trimestrelle de Droit Européen, 47, n. ${ }^{\circ}$ 1, (2011): 136; Wolfgang Wessels, «The European Council: beyond the traditional view towards a fusion», en Melanges en l'honneur de Jean Paul Jacqué. (Paris, Dalloz, 2010): 751. 
Además, el art. 133 RPE ha extendido esa fiscalización, habilitando a cualquier diputado, grupo político o comisión a formular preguntas con solicitud de respuesta escrita al Presidente del Consejo Europeo, el cual, por tanto, «a sensu contrario», se libra así de las preguntas orales y del turno de preguntas del que no se exime a los presidentes de las demás instituciones de la Unión. Estamos, pues, en presencia, de una forma devaluada de control, que, si bien conviene no despreciar, ya que puede estar llamada a cobrar una importancia creciente, si el Parlamento hace un uso intenso de sus facultades con respecto a la misma, lo cierto es que, en ningún caso, comporta exigencia alguna de responsabilidad política.

La comparecencia parlamentaria del Presidente del Consejo Europeo ante el Parlamento Europeo tiene como correlato el derecho que el TFUE garantiza al Presidente de la Cámara a ser escuchado, en las ocasiones en que se le invite a asistir a las reuniones del Consejo Europeo (art. 235.2 TFUE). La combinación de ambas previsiones ha permitido, teniendo, a este respecto, muy en cuenta la personalidad de sus presidentes, la creación de un cierto vínculo de confianza entre las dos instituciones, que se ha manifestado en la celebración de frecuentes contactos de carácter informal entre sus máximos representantes ${ }^{56}$.

Con todo, a pesar de los progresos alcanzados, también cabe constatar un retroceso con respecto a la práctica seguida desde la aprobación del Tratado de Maastricht, ya que, conforme a éste, el Consejo Europeo se veía obligado a remitir, asimismo, al Parlamento Europeo un informe anual acerca de los progresos alcanzados por la Unión ${ }^{57}$. Pues bien, dicho compromiso no sólo ha desaparecido de los Tratados, sino, incluso, del propio Reglamento interno del Consejo Europeo, que también lo contemplaba ${ }^{58}$. Por tanto, ha de insistirse en que la relación entre ambas instituciones continúa siendo claramente insatisfactoria, discurriendo preferentemente a través de cauces apenas formalizados. Y sorprende que así sea si se consideran los decisivos cometidos políticos que el Consejo Europeo tiene encomendados, a la luz del art. 15 TEU $^{59}$. Que los miembros de esta institución, y su presidente, no hayan sido elegidos por el Parlamento Europeo, sino por los Estados miembros a los que representan y ante los cuales deben sus miembros, en su caso, rendir cuentas, de acuerdo con el doble principio de legitimidad

56 Vérane Edjaharian, «Article 15: the European Council», en The Treaty on the European Union. A Commentary, eds. Hermann Joseph Blanke \& Stelio Mangiameli, (Heildelberg, Springer, 2013): 641.

57 Artículo 4.3 TUE (versión Niza).

58 Cfr. Art. 5.2 de la Decisión del Consejo Europeo de 1 de diciembre de 2009, por la que se adopta su Reglamento interno (2009/882(UE) (DO L 2.12.2009).

59 Vérane Edjaharian, «Article 15: the European Council», op. cit., 640. 
que se proyecta sobre las instituciones políticas europeas, de conformidad con el art. 10.2 TUE, se ha convertido en una coartada que, en la práctica, exime a esta institución, considerada como tal, de toda responsabilidad por sus actos, en el ámbito de la Unión en el cual aquéllos se desarrollan. Consiguientemente, al no facultarse al Parlamento Europeo para que exija una completa rendición de cuentas al Consejo Europeo, de la que pueda derivarse la eventual imposición de sanciones apreciables, se impide la plena conformación de un sistema de gobierno autónomo e integrado en el seno de la Unión ${ }^{60}$. Este hecho, revelador de las resistencias que sigue ofreciendo el sometimiento conjunto de las actuaciones de todas las instituciones políticas europeas a un control parlamentario efectivo y centralizado, manifiesta, a la postre, la irradiación incompleta del principio democrático en la arquitectura institucional comunitaria ${ }^{61}$.

Por el contrario, a diferencia de lo que sucede con el Consejo Europeo, el Consejo se halla en una situación, en principio, distinta, al mantener una relación fluida y constante con el Parlamento Europeo, dado que, de forma conjunta con esta institución, ejerce funciones legislativas y presupuestarias (art. 16.1 TUE) ${ }^{62}$. No obstante, también lleva a cabo una relevante labor, desligada del Parlamento, de «definición de políticas y de coordinación, en las condiciones establecidas en los Tratados» (arts. 16 TUE y 237 a 243 TFUE). Tal función le faculta para armonizar los intereses de los Estados, en aras de satisfacer el interés superior de la Unión. Por tanto, ese cometido autónomo que se le atribuye, consistente en la definición del interés común, tras confrontar los respectivos intereses nacionales, es fuente de una voluntad propia, distinta de la de los diferentes Estados miembros. De ahí que sus decisiones se impongan a éstos en las materias objeto de su competencia. Así, en desarrollo de esa función, el Consejo adopta, también, ya actos no legislativos, expresamente previstos en los Tratados, ya otros, orientados a desarrollar actos legislativos (arts. 31, 42, 43.3, 74, 75, 78.3, 79, 81.3.2..$^{\circ}$ y 95.3 TFUE) ${ }^{63}$.

${ }^{60}$ Carol Harlow, Accountability in the European Union, op. cit., 86; Vernon Bogdanor, Legitimacy, accountability and democracy in the European Union, op . cit., 424.

61 José María Porras Ramírez, «Article 10: representative democracy», en The Treaty on the European Union. A Commentary, eds. Hermann Joseph Blanke \& Stelio Mangiameli (Heildelberg, Springer, 2013): 424.

62 Deirdre Curtin, Executive power of the European Union. (Oxford, Oxford University Press, 2009): 34.

63 Acerca de la naturaleza del Consejo, vid. Fiona Hayes-Renshaw \& Helen Wallace, The Council of Ministers, (New York, McMillan, 2006): 34. Y, también, Josu de Miguel Bárcena, «El Consejo de la Unión Europea. Poder normativo y dimensión organizativa», (Madrid, Thomson-Civitas, 2009): 54. Barbara Guastaferro, «Il Consiglio dell’Unione Europea: composizione, funzioni e procedure decisionali», en, Dal Trattato costituzionale al Trattato di Lisbona. Studi sulla Costituzione europea, ed, por Alberto Lucarelli-Andrea Patrone-Griffi (Roma, Edizione Scientifiche Italiane, 2004): 437. 
En particular, el Derecho primario u originario de la Unión ha querido que el Consejo, en su formación como Consejo de Asuntos Económicos y Financieros (ECOFIN), sea quien supervise la evolución económica de cada uno de los Estados miembros y de la Unión, y determine la coherencia de tales políticas económicas con las orientaciones generales (arts. 120 y 121 TFUE). Y son, también, los Tratados quienes asignan al Consejo el cometido de reforzar la coordinación y supervisión de su disciplina presupuestaria (art. 136 TFUE); coordinar la estrategia para el empleo (arts. 145 y 146 TFUE); coordinar la salud pública (art. 168 TFUE); las redes transeuropeas (art. 171.2 TFUE); la industria (art. 173 TFUE); la cohesión económica, social y territorial (arts. 175 TFUE); la investigación y la política espacial (arts. 181 y 189 TFUE); las políticas estatales de cooperación al desarrollo (art. 210 TFUE); el recurso a la cláusula de solidaridad (art. 220 TFUE); y la lucha contra el fraude (art. 325 TFUE), entre otros objetivos destacables.

A su vez, han de subrayarse las competencias que asume el Consejo en materia de relaciones económicas exteriores, materia ésta que se deja bajo su responsabilidad. Así, es quien autoriza la apertura de negociaciones para adoptar acuerdos internacionales y quien manifiesta el consentimiento de la Unión, tanto en los acuerdos comerciales y de asociación, como en otros de carácter económico ${ }^{64}$. Y aparece, asimismo, como la institución encargada de adoptar decisiones referidas a la Política Exterior y de Seguridad Común, de gran trascendencia general (art. 24 TUE, en relación a los arts. 40 TUE y 263 y 275 TFUE).

En atención, por tanto, a la relevancia de sus actuaciones políticas, ajenas al ejercicio de las funciones legislativa y presupuestaria, se impone su comparecencia ante el Parlamento, en cumplimiento de su deber genérico de información, pues sólo, de ese modo, se hará posible el exacto conocimiento y consiguiente control político de aquéllas. En este sentido, el Consejo comparece ante el Parlamento, bien a solicitud propia, a fin de expresar sus opiniones mediante la presentación de una declaración escrita, en situaciones concretas ${ }^{65}$. Pero también debe hacerlo, obligatoriamente, al inicio y al final del mandato de su presidencia semestral. En ambas ocasiones, el miembro del Consejo que represente al Estado miembro que ejerza la Presidencia del Consejo, presentará al Parlamento Europeo las prioridades de su Presidencia y los resultados alcanzados durante el semestre ${ }^{66}$. De este modo, la Cámara dispondrá de la posibilidad de evaluar, en dos momentos distintos, al inicio y al final, tanto las propues-

${ }^{64}$ Francisco Jesús Carrera Hernández (Dir), ¿Hacia una nueva gobernanza económica de la Unión Europea? (Madrid, Thomson Reuters Aranzadi, 2018): 12.

65 Art. 26.3 del Reglamento interno del Consejo.

66 Art. 5.3 del Reglamento interno del Consejo Europeo. 
tas como los logros obtenidos por la presidencia semestral del Consejo, expresando su posición al respecto. Tales declaraciones serán seguidas del correspondiente debate, el cual permitirá vislumbrar las distintas valoraciones que suscita el proceder de dicha institución, y, posteriormente, de una eventual resolución, expresiva de la posición común adoptada por el Parlamento ${ }^{67}$.

Por lo demás, en su trato ordinario con la Cámara, y de conformidad con el artículo 26.1 de su propio Reglamento interno ${ }^{68}$, están autorizados a representar al Consejo ante el Parlamento Europeo o sus comisiones: quien ostente «la Presidencia del Consejo o, con el acuerdo de ésta, un miembro del grupo predeterminado de tres Estados miembros contemplados en el artículo 1, apartado 4, la Presidencia siguiente o el Secretario General». Así sucederá en relación a los asuntos más importantes, de los que se dará cuenta ante el Pleno de la Cámara. De los demás se ha previsto que «por mandato de la Presidencia», el Consejo también pueda hacerse representar en las comisiones del Parlamento Europeo por altos funcionarios de la Secretaría General. Dicha delegación no es necesario que sea formal, sino que bastará con que la Presidencia haya declarado su intención al respecto, de forma clara y precisa, comunicándosela así a la Cámara.

Por cuanto concierne a su formación como Consejo de Asuntos Exteriores, de conformidad con el art. 26.2 de dicho Reglamento interno se determina que su Presidente, que no es otro que el Alto Representante de la Unión para Asuntos Exteriores y Política de Seguridad, a un tiempo Vicepresidente de la Comisión Europea (art. 18 TUE), sea quien se encargue «de representar al Consejo en el Parlamento Europeo y sus comisiones» ${ }^{69}$. Sin embargo, de modo escasamente coherente con la creación específica de su figura, se ha previsto, cuestionablemente, que dicho Alto Representante pueda, «si es necesario, hacerse sustituir por el miembro de esta formación que represente al Estado miembro que ejerza la Presidencia semestral del Consejo». Asimismo, subsidiariamente, y de modo no menos criticable, se faculta a dicho Alto Representante para que otorgue a altos funcionarios del Servicio Europeo de Acción Exterior o, cuando proceda, de la Secretaría General, mandato para representar al Consejo de Asuntos Exteriores ante comisiones del Parlamento Europeo.

67 Art. 132 RPE.

68 Decisión del Consejo de 1 de diciembre de 2009 por la que se adopta el Reglamento interno del Consejo (2009/937/UE. DO L 11.12.2009, p. 35)

69 Vid., a título de ejemplo, la pregunta prioritaria escrita dirigida a dicho Alto Representante acerca del suministro a través de puertos europeos de combustible a jets rusos destinados a la zona de conflicto armado de Siria. P-004470/2019 http://europarl.europa.eu/plenary/ es/parliamentary-questions.html 
Dichas sustituciones merecen un justificado rechazo, habida cuenta de que están concebidas para evitar la confrontación del representante político responsable del Consejo con el órgano parlamentario de control establecido, designado receptor de la información. No en vano, suponen la descarga en un funcionario (habitualmente un director general), por lo demás obligado a atenerse a las estrictas instrucciones procedentes de la Secretaría General del Consejo, las cuales le prohíben imperativamente contraer compromiso alguno, a menos que disponga de un mandato expreso y claro a estos efectos, de un cometido que trasciende el mero deber de información de los actos del Consejo, ya que constituye el presupuesto de la actividad de fiscalización política que le corresponde desempeñar a la Cámara, en relación con aquéllos ${ }^{70}$.

En todo caso, el alcance del control que el Parlamento puede ejercer con respecto al Consejo es considerablemente más intenso que el que se le permite realizar en relación con el Consejo Europeo. Así, conforme al art. $136 \mathrm{RPE}$, se establece que una comisión, un grupo político o un número de diputados que alcancen, al menos, el umbral mínimo de la Cámara, podrán formular preguntas de respuesta oral, seguidas de debate al Consejo, y solicitar su inclusión en el orden del día del Parlamento. Las preguntas dirigidas al Consejo se transmitirán, al menos, tres semanas antes de la sesión en cuyo orden del día deban incluirse, hecho éste que constituye, sin duda, la expresión de un claro trato de favor. Además, se ha previsto que, cuando dichas preguntas se refieran a la política común de seguridad y defensa, no exista, siquiera, plazo alguno para su respuesta, que será, a lo sumo, el «razonable para mantener informado al Parlamento». Cuando menos, tras la contestación a las preguntas, se suscitará un debate y la votación de propuestas de resolución. Además, el Consejo puede verse, también, sometido a turnos de preguntas específicos, según ha previsto el art. 137.3 RPE. Y, asimismo, se contempla que cualquier diputado, grupo político o una comisión puedan formular preguntas con solicitud de respuesta escrita a esa institución (art. 138 RPE) ${ }^{71}$. Finalmente, según el art. 139 RPE, el Consejo podrá ser objeto de interpelaciones con solicitud de respuesta escrita, las cuales se verán seguidas de debate y resolución.

70 Igual sucederá cuando sea el Parlamento Europeo quien, con arreglo al art. 226 TFUE, constituya una comisión temporal de investigación y demande la comparecencia de un representante del Consejo.

71 Vid., por ejemplo, la pregunta prioritaria escrita dirigida al Consejo acerca de los planes nacionales 2030 de energía y clima en el marco del Acuerdo Verde Europeo. P-004463/2019. http://europarl.europa.eu/plenary/es/parliamentary-questions.html 
Todo lo indicado demuestra que el alcance paulatinamente adquirido por la función parlamentaria de control sobre las actuaciones del Consejo, aunque mejorable, no es nada desdeñable, a pesar de los obstáculos y limitaciones interpuestos para su más eficaz ejercicio, los cuales convendría allanar.

\section{Conclusiones}

En vistas del panorama expuesto y analizado, es claro que el modelo de seguimiento, supervisión y fiscalización de las actividades de la Comisión por parte del Parlamento Europeo responde cabalmente a las exigencias de una democracia avanzada. No en vano, la Comisión ha asumido un deber constante de información a la Cámara, que se sustancia a través de las más diversas formas de comparecencia y suministro documental de datos e informes. Tal hecho garantiza su intercambio, facilita los acuerdos y asegura el control universal y efectivo de sus actos, que puede llegar a comportar la asunción de responsabilidades. Semejante función de control se materializa ordinariamente a través de instrumentos complementarios, empleados de forma reiterada y continua, como son las preguntas orales, las escritas, la realización del turno de preguntas y las interpelaciones.

Sin embargo, esa colaboración e intercambio de información con el Parlamento Europeo no se observa, en igual proporción, con las otras dos instituciones de carácter intergubernamental y naturaleza política que concurren en el desarrollo de la gobernanza política de la Unión. Por tanto, si bien el Consejo y el Consejo Europeo también están llamados a dar cuenta de sus actuaciones ante la Cámara, lo harán «en las condiciones fijadas por el (respectivo) reglamento interno»; privilegio éste que disminuye considerablemente su alcance, lo que se hace particularmente evidente en el caso del Consejo Europeo. De ese modo, a pesar de los sustanciales avances experimentados, dicho control, en lo que, particularmente, a esta última institución se refiere, sigue, en buena medida, discurriendo a través de cauces apenas formalizados, que no habilitan, en ningún caso, la posibilidad de exigencia de responsabilidad política.

Consecuentemente, ha de postularse la completa extensión, si bien adaptada a sus peculiaridades, del modelo de información y control establecido entre el Parlamento y la Comisión, que tan buenos resultados viene ofreciendo en las últimas décadas, suprimiendo así las «inmunidades del poder» que aún se siguen apreciando. Dicha propuesta no pretende sino contribuir al debate en curso acerca de las reformas institucionales que han de afectar al desarrollo de la gobernanza de la Unión, avanzando así en el proceso constante e ininterrumpido de democratización progresiva de sus estructuras políticas. 


\section{Sobre el autor}

José María Porras Ramírez es Doctor en Derecho, Catedrático de Derecho Constitucional de la Universidad de Granada y Catedrático Jean Monnet de Derecho Constitucional Europeo. Desarrolló su formación académica en el Centro de Estudios Políticos y Constitucionales de Madrid y en las Universidades de Florencia, Regensburg, Bayreuth y Roma (La Sapienza). Es autor de más de ciento veinte publicaciones, entre las que destacan sus cinco monografías: "Principio democrático y función regia en la Constitución normativa»; "El conflicto en defensa de la autonomía local ante el Tribunal Constitucional»; "Libertad religiosa, laicidad y cooperación con las confesiones en el Estado democrático de Derecho»; "Reformas estatutarias y nuevo sistema autonómico de fuentes del Derecho»; e "Integraçâo supranacional: dimensôes da proteçâo multinivel dos direitos e sistema do governo da Uniâo Europeia». Ha impartido conferencias sobre cuestiones de su especialidad en prestigiosas Universidades de todo el mundo y participado como ponente en más de cincuenta congresos internacionales celebrados en Europa y América. Actualmente es miembro del consejo editorial de diez revistas internacionales. Y forma parte del equipo internacional que realiza el comentario sistemático de los Tratados constitutivos de la Unión Europea.

\section{About the author}

José María Porras Ramírez, Doctor of Law, Full Professor of Constitutional Law at the University of Granada and Jean Monnet Professor of European Constitutional Law. He developed his academic training at the Center for Political and Constitutional Studies in Madrid and at the Universities of Florence, Regensburg, Bayreuth and Rome (La Sapienza). He is the author of more than one hundred and twenty publications, among which should be highlighted his five monographs: «Democratic principle and royal function in the normative Constitution»; "The conflict in defense of local autonomy before the Constitutional Court»; «Religious freedom, public neutrality and cooperation with confessions in the democratic State»; «Statutory reforms and new autonomous system of sources of law»; and «Supranational integration: dimensions of multilevel protection of fundamental rights and on system of government of the European Union». He has lectured on issues of his specialty in prestigious universities around the world and participated as a speaker at more than fifty international conferences held in Europe and America. He is currently a member of the editorial board of ten international journals. And he is part of the international team that makes the systematic comment of the Treaties establishing the European Union. 


\section{Derechos de autor}

Los derechos de autor (para la distribución, comunicación pública, reproducción e inclusión en bases de datos de indexación y repositorios institucionales) de esta publicación (Cuadernos Europeos de Deusto, CED) pertenecen a la editorial Universidad de Deusto. El acceso al contenido digital de cualquier número de Cuadernos Europeos de Deusto es gratuito inmediatamente después de su publicación. Los trabajos podrán leerse, descargarse, copiar y difundir en cualquier medio sin fines comerciales y según lo previsto por la ley; sin la previa autorización de la Editorial (Universidad de Deusto) o el autor. Así mismo, los trabajos editados en CED pueden ser publicados con posterioridad en otros medios o revistas, siempre que el autor indique con claridad y en la primera nota a pie de página que el trabajo se publicó por primera vez en CED, con indicación del número, año, páginas y DOI (si procede). Cualquier otro uso de su contenido en cualquier medio o formato, ahora conocido o desarrollado en el futuro, requiere el permiso previo por escrito del titular de los derechos de autor.

\section{Copyright}

Copyright (for distribution, public communication, reproduction and inclusion in indexation databases and institutional repositories) of this publication (Cuadernos Europeos de Deusto, CED) belongs to the publisher University of Deusto. Access to the digital content of any Issue of Cuadernos Europeos de Deusto is free upon its publication. The content can be read, downloaded, copied, and distributed freely in any medium only for non-commercial purposes and in accordance with any applicable copyright legislation, without prior permission from the copyright holder (University of Deusto) or the author. Thus, the content of CED can be subsequently published in other media or journals, as long as the author clearly indicates in the first footnote that the work was published in CED for the first time, indicating the Issue number, year, pages, and DOI (if applicable). Any other use of its content in any medium or format, now known or developed in the future, requires prior written permission of the copyright holder. 